\title{
THE EFFECT OF INDIVIDUAL SELECTION FOR GENETIC DIVERSITY OF Acacia mangium SEEDLING SEED ORCHARD USING AFLP MARKERS
}

\author{
AYPBC Widyatmoko ${ }^{1}$, S. Shiraishi ${ }^{2}$, A. Nirsatmanto ${ }^{1}$, and H. Kawazaki ${ }^{3}$
}

\begin{abstract}
Establishment of seed orchard is aimed at producing good quality seeds which is an important activity for breeding program. Seed orchard is also a base population, thus its genetic diversity is depending on its design and composition (provenance, family and individual tree). Selection of an individual tree in seed orchard is needed for the enhancement of retaining good-character trees. However, selection of individual tree can change the genetic diversity of seed orchard, and the degrees to which the genetic diversity will change depend on the used selection methods. In order to investigate the effects of selection methods, 4 simulations of selection methods based on height, diameter and stem performance of individual trees were used. The differences among the 4 methods were the ranking of individual trees those selected, and families and provenances those have been represented. Seedling seed orchard of Acacia mangium in Wonogiri, Central Java was used as materials.

Analysis of genetic diversity was carried out using AFLP markers. Nine primer combinations were used to produce 1025 AFLP banding patterns. Among those banding patterns, only 109 were polymorphic markers. No significant effect of individual tree selection was revealed in this study. Even though the selection was done intensively, only $7.1 \%$ of genetic diversity was reduced. In other words, the selection activity did not reduce the genetic diversity of seed orchard significantly. The result is important for developing future tree improvement of $A$. mangium, including development of hybrid between $A$. mangium and $A$. auriculiformis.
\end{abstract}

Keywords: Acacia mangium, selection, AFLP, genetic diversity

\section{INTRODUCTION}

Genetic diversity provides a template for adaptation and evolution of species and individuals, especially in forest tree populations. Since genetic diversity is a key component for the sustainability of forest resource, maintenance of genetic diversity becomes an important objective of biodiversity conservation and tree-breeding operation. Forest management practices such as clear-cut harvesting followed by natural and/or artificial regeneration can significantly have a considerable impact on genetic diversity. In a forest tree breeding program, genetic diversity of forest trees can be reduced by phenotypic selection breeding (tree improvement cycle) and seed and seedling production. Thus, monitoring

\footnotetext{
${ }^{1}$ Forest Plantation Research and Development Center, Indonesia

${ }^{2}$ Laboratory of Silviculture, Faculty of Agriculture, Kyushu University, Fukuoka, Japan

${ }^{3}$ Tohoku Regional Breeding Office, Iwate 020-0173, Japan
} 
genetic diversity in a tree breeding and production populations is needed. It is not only for gauging the impact of breeding and production activities on reforestation stock, but also for effective genetic conservation of existing natural population (El-Kassaby, 1996).

Various studies have been done to investigate the effects on forest management practices for genetic diversity of forests (Knowles, 1985; Bergmann and Ruetz, 1991; Gomory, 1992; El-Kassaby, 1996; Thomas et al., 1999; Rajora et al., 2000). Acacia species is one important species producing raw materials for pulp and paper industries. By year 2000 there may be more than one million hectares of tropical Acacia plantations in South-East Asia and China, especially A. mangium (Balodis and Clark, 1998).

In order to support it's wood industry, since 1985 the Indonesian Government (c.q. Ministry of Forestry) has started a forest timber estate program. The program is aimed at establishing plantations of some potential species to produce raw material for wood industry, and one of them is $A$. mangium. Recently the breeding program of this species is progressing well toward producing a high quality of wood. Establishment of seed orchard is an important activity for breeding program for producing a good quality of seeds. Selection of individual tree in a seed orchard is needed for the enhancement of retaining good-character trees. However, selection of individual tree can change the genetic diversity of a seed orchard, and the degrees to which the genetic diversity will change depends on the methods of selection. Genetic diversity of $A$. mangium has been studied elsewhere using isozyme analysis (Moran et al., 1988; Khasa et al., 1994) and RFLP (Butcher et al., 1998). However, the change in the genetic diversity of seed orchards due to selection activities is still unknown.

Amplified fragment length polymorphism (AFLP) is one of the most powerful methods for DNA fingerprinting (Vos et al., 1995). These markers have been widely employed due to their effectiveness and reliability. Studies on genetic diversity have already been carried out with AFLPs in numerous plants like Salix spp. (Barker et al., 1999), Olea europaea (Angiollilo et al., 1999), Arabidopsis thaliana (Breyne et al., 1999) and Pinus sylvestris (Lerceteau and Szmidt, 1999). Some studies have been done in order to improve the reliability of AFLP for detecting genetic diversity of plant (Cervera et al., 2000; Treuren, 2001).

In this study, we used the AFLP markers to evaluate the effect of individual selection in A. mangium seedling seed orchard in Wonogiri, Central Java, Indonesia. The result of this study will be important for developing the strategy of breeding program of $A$. mangium, included the importance of hybrid between $A$. mangium and $A$. auriculiformis.

\section{MATERIALS AND METHODS}

\section{A. Materials}

A total of 57 individual trees of $A$. mangium were collected from seedling seed orchard of $A$. mangium after second selection within plot in Wonogiri, Central Java, Indonesia. Total number of populations, families and replications in the seedling seed orchard were 15, 134 and 7 respectively. 


\section{B. Methods}

In order to detect the effect of selection, 4 simulations of selection method were used. Each method contained 25 individual trees. All trees in the seedling seed orchard were ranked based on straightness and volume data (height and diameter). The detail condition of four selection methods was described in Table 1.

Table 1. Outline of four selection methods

\begin{tabular}{|c|c|c|c|}
\hline No. & $\begin{array}{l}\text { Selection } \\
\text { method }\end{array}$ & Condition & $\begin{array}{l}\text { Number of } \\
\text { individual }\end{array}$ \\
\hline 1. & Random & $\begin{array}{l}25 \text { individual trees were selected randomly from } \\
\text { all trees retained in the seedling seed orchard }\end{array}$ & 25 \\
\hline 2. & Method I & The highest ranking of 25 trees & 25 \\
\hline 3. & Method I I & $\begin{array}{l}\text { Similar to Method I except } 1 \text { family was } \\
\text { represented by only } 1 \text { individual tree }\end{array}$ & 25 \\
\hline 4. & Method III & $\begin{array}{l}\text { Similar to Method II, but each population was } \\
\text { represented by maximum of } 2 \text { individual trees }\end{array}$ & 25 \\
\hline
\end{tabular}

Total genomic DNA was extracted using a modified CTAB protocol reported by Shiraishi and Watanabe (1995). The DNA was purified using Gene Clean III (BIO101) as a template for further analyses. Procedures for AFLP basically followed the protocol developed by Vos et al. (1995). Briefly, approximately $250 \mathrm{ng}$ of total genomic DNA was digested by 2.5 units of EcoRI and 2.5 units of MseI. Subsequently, AFLP adapters for both restriction enzymes were ligated to the fragments. Template DNA was then preamplified using primer pairs based on sequence of the adapters but 3 ' extended with one selective nucleotide. Preamplification product was diluted 10 times and used as template in a second amplification reaction. Primers used in the second amplification were the preamplification primers plus 3 selected nucleotide at the 3 ' end. The EcoRI primer was radiolabelled with 33P prior to PCR. Labelled PCR product was mixed with the same volume of formamide buffer (98\% formamide, 10 mM EDTA, pH 8.0, 0.05\% blue dextran EDTA and 0.05\% Gene Scan ROX). After denaturation for 2 minutes at $94^{\circ} \mathrm{C}, 2 \mu \mathrm{l}$ of the reaction were separated on $4.5 \%$ acrylamide/bis 19:1, 7.5M urea and 1xTBE for 12 hours.

The presence (1) or absence (0) of the polymorphic fragments attained from electrophoresis was noted as $1 / 0$ data. Based on this data, genetic distance $(D=1-S)$ among individuals were calculated using a simple matching coefficient (Sokal and Michener, 1958). In this study, the mean of genetic distance among individuals was assumed to be the genetic diversity of the group/method. 


\section{RESULT AND DISCUSSION}

\section{A. Genetic Distance of Four Selection Methods}

The number of bands scored for the 9 primer combinations ranged from 77 up to 136 with the mean of 113 markers/primer combination. In total, 1025 were scored with 109 $(10.6 \%)$ polymorphic markers. The number of markers obtained from AFLP of $A$. mangium was bigger compared to that obtained from other past analysis using isozyme and RFLP analysis. Moran et al. (1988) used 30 enzyme systems and the number of polymorphic alleles was 19. Butcher et al. (1998) used RFLP analysis to estimate genetic diversity of nuclear genome of $A$. mangium. By using 50 probes, 57 putative Mendelian loci were revealed and 46 of them were polymorphic. In this study, only about $10 \%$ of AFLP banding patterns were polymorphic markers. It mean that the genetic diversity of $A$. mangium is quite low. This percentage value was lower than the figures reported for Salix spp. (81.8\%; Barker et al., 1999) and Pinus sylvestris L. (69.1\%; Lerceteau and Szmidt, 1999).

Number of families, population, ranking and mean of genetic distances between individual of each selection methods are shown in Table 2. The 25 trees in method I, II, and III revealed almost no significant difference in ranking. Thus, even though there was an intense degree of tree selection, of the ranking of the 25 trees did not change significantly. The number of population was not increased significantly by increasing the intensity of selection. Method I and method II contained the same populations (data not shown). This result showed that the highest rank of the trees was distributed in all populations. The populations used for sampling in this study were taken from Papua New Guinea Provenances ( 8 populations) and Cape York of Australia Provenances ( 7 populations), two regions with high genetic diversity (Butcher et al., 1998). However, Bucther et al. (1998) detected that in those regions proportion of variation among populations was very low compared to other regions.

Table 2. Mean of genetic distance of each selection method

\begin{tabular}{|l|c|c|c|c|c|}
\hline $\begin{array}{c}\text { Selection } \\
\text { method* }\end{array}$ & $\begin{array}{c}\text { Family } \\
\text { number }\end{array}$ & Ranking & $\begin{array}{c}\text { Population } \\
\text { number }\end{array}$ & $\begin{array}{c}\text { Mean of genetic } \\
\text { distance between } \\
\text { individual }\end{array}$ & $\begin{array}{c}\text { Percentage } \\
(\%)\end{array}$ \\
\hline Random & 25 & - & 13 & $0.042 \pm 0.007$ & 100 \\
Method I & 23 & $1-25$ & 12 & $0.040 \pm 0.007$ & 95.2 \\
Method II & 25 & $1-27$ & 12 & $0.039 \pm 0.007$ & 92.9 \\
Method III & 25 & $1-47$ & 15 & $0.040 \pm 0.007$ & 95.2 \\
\hline
\end{tabular}

Remark : ${ }^{*}=$ Criteria of the selection methods was shown in Table 1 
Mean genetic distance of individual trees in each method was 0.042, 0.040, 0.039 and 0.040 for random, method I, method II and method III, respectively. With exception of random selection, the other three methods had a similar mean of genetic distance. These values mean that individual trees closely related, or there was a low diversity in the trees in each method.

If the genetic diversity value of 25 trees selected in the random selection were assumed to be the base genetic diversity of the seedling seed orchard, the value obtained in this result revealed that there was a very low genetic diversity of $A$. mangium. Eventhough AFLPs markers like RFLPs markers which detect the DNA level in both coding and non-coding regions, the result of genetic diversity of $A$. mangium using AFLP markers was almost similar with the result of using isozyme analysis (Moran et al., 1988 and Khasa et al., 1994), and was quite low compared with that obtained using RFLP markers (Butcher et al., 1998). Butcher et al. (1998) explained that the detection of higher level of variation using RFLPs may reflect fundamental differences between the marker types. In this study, the number of AFLPs markers was almost twice and the number of samples per population was smaller than the analysis using RFLP.

Assuming result of genetic diversity of random selection is $100 \%$, the effect of the other 3 methods ranged from 4.8 to $7.1 \%$. Thus, a significant effect of individual tree selection was not revealed in this study. A similar result was also reported by El-Kassaby (1996) who indicated that early selection and breeding of a highly polymorphic species did not significantly reduce genetic variation. Other studies investigating the effect of management practices also showed no significant effect in the genetic diversity of forests (Knowles, 1985; Bergmann and Ruetz, 1991; Gomory, 1992; El-Kassaby, 1996; Thomas et al., 1999; Rajora et al., 2000).

\section{B. Application for Mangium Breeding Program}

The seed production is a combination between trees inside the seed orchard, thus a wide genetic base and a little percentage of inbreeding are the most important points. Combined with selection activity, a seed orchard can provide a high genetic gain.

The significant effect of individual tree selection method was not revealed in this study. Even though the selection was done intensively, only $7.1 \%$ of genetic diversity was reduced. In other words, the selection activity did not reduce the genetic diversity of seed orchard significantly. Thus, in order to reduce inferior trees in the seedling seed orchard, any kind of selection method can be used. Since the seedling seed orchard contained mostly trees from Papua New Guinea and Cape York populations, hence relatively low genetic variation among populations, the selection should be concentrated to individual selection instead of population selection. Another method to enrich the genetic base of the seedling seed orchard is by introducing new trees (infuse) from other regions (El-Kassaby, 1996), especially from Townsville or Daintree and Ceram or Sidei populations (Butcher et al., 1998).

The previous reports on genetic diversity of $A$. mangium and the result obtained in this study revealed a quite low genetic diversity of $A$. mangium. Based on this information, the establishment of seed orchard for future tree improvement program of $A$. mangium should be distinguished into 2 programs. In the case of establishing seed orchard of $A$. mangium only, all genetic material of the species must be collected. Thus, the genetic base of the seed orchard 
should be as high as genetic diversity of $A$. mangium. Since the hybrid between $A$. mangium and $A$. auriculiformis suggested better performance compared to its parents (Sedgley et al., 1992), the other program is to establish a hybrid seed orchard. This program would not limited to increase the genetic base of seed orchard, but also produce better material for pulp and paper industry.

\section{CONCLUSION}

Based on the result of our present study, some conclusions can be obtained as follows:

1. Among the 1025 AFLP banding patterns, only 109 were polymorphic markers. Therefore, genetic diversity of $A$. mangium is very low.

2. Using 4 simulation methods of selection, the effect of individual tree selection was not significant. Thus, reducing inferior trees in the seed orchard can be done through any kind of selection methods.

3. The tree improvement strategy of $A$. mangium should be distinguished into 2 programs, namely strategy for only $A$. mangium species and combination with $A$. auriculiformis.

\section{ACKNOWLEDGEMENT}

The authors express their appreciation to the Centre for Plantation Forest Research and Development as well as Biotechnology Tree Improvement office and JICA (Japan International Cooperation Agency) in Yogyakarta for the materials support. Special thanks to Dr. Atsushi Watanabe for his suggestion on the manuscript, and students of the Laboratory of Silviculture, Faculty of Agriculture, Kyushu University for their laboratory assistances.

\section{REFERENCES}

Angiolillo, A., M. Mencuccini, and L. Baldoni. 1999. Olive genetic diversity assessed using amplified fragment length polymorphism. Theor. Appl. Genet. 98: 411 - 421.

Balodis, V. and N. B. Clark. 1998. Tropical acacias - the new pulpwood. Appita J. 51: 179 181.

Barker, J. H. A., M. Matthes, G. M. Arnold, K. J. Edwards, I. Ahman, S. Larsson, and A. Karp. 1999. Characterization of genetic diversity in potential biomass willows (Salix spp.) by RAPD and AFLP analyses. Genome 42:173 - 183.

Bergmann, F. and W. Ruetz. 1991. Isozyme genetic variation and heterozygosity in random tree samples and selected orchard clones from the same Norway spruce populations. For Ecol. Mgmt. 46: 39 - 47.

Breyne, P., D. Rombaut, A. V. Gysel, M. V. Montagu, and T. Gerats. 1999. AFLP analysis of genetic diversity within and between Arabidopsis thaliana ecotypes. Mol. Gen. Genet. 261: 627-634. 
Butcher, P. A., Moran, G. F. and Perkins, H. D. 1998. RFLP diversity in the nuclear genome of Acacia mangium. Heredity 81: 205 - 213.

Cervera, M. T., D. Remington, J. M. Frigerio, V. Storme, B. Ivens, W. Boerjan, and C. Plomion. 2000. Improved AFLP analysis of tree species. Can J. For. Res. 30: 1608 - 1616.

El-Kassaby, Y. A. 1996. Impact of selection and breeding on the genetic diversity in Douglasfir. Biodiversity and Conservation 5: 795 - 813.

Gomory, D. 1992. Effects of stand origin on the genetic diversity of Norway spruce (Picea abies Karst.) populations. For. Ecol. Mgmt. 54: 215 - 223.

Khasa, P. D., W. M. Cheliak, and J. Bousquet. 1994. Genetic variation in 26 populations of Racosperma auriculiforme and Racosperma mangium using allozymes. Can. J. For. Res. 24: $1123-1132$.

Knowles, P. 1985. Comparison of isozyme variation among natural stands and plantations: jack pine and black spruce. Can J. For. Res. 15: 902 - 908.

Lerceteau, E. and A. E. Szmidt. 1999. Properties of AFLP markers in inheritance and genetic diversity studies of Pinus sylvestris L. Heredity 82: 252 - 260.

Moran, G. F., O. Muona, and J. C. Bell. 1988. Acacia mangium: A tropical forest tree of the coastal lowlands with low genetic diversity. Evolution 43: 231 - 235.

Rajora, O. P., M. H. Rahman, G. P. Buchert, and B. P. Dancik. 2000. Microsatellite DNA analysis of genetic effects of harvesting in old-growth eastern white pine (Pinus strobus) in Ontario, Canada. Molecular Ecology 9: 339 - 348.

Shiraishi, S. and A. Watanabe. 1995. Identification of chloroplast genome between Pinus densiflora Sieb. et Zucc. and P. thunbergii Parl. based on the polymorphism in rbcL gene. J. Jpn. For. Soc. 77: 429 - 436 (in Japanese with English summary).

Sedgley, M., J. Harbard, R.M. Smith, R. Wickneswari and A. R. Griffin. 1992. Reproductive biology and interspecific hybridization of Acacia mangium and A. auriculiformis A. Cunn. ex Benth. (Leguminosae: Mimosoideae). Australian Journal of Botany 40: 37 - 48.

Sokal, R. R. and C. D. Michener. 1958. A Statistical method for evaluating systematic relationships. The University of Kansas Science Bulletin. 38: 1409 - 1438.

Thomas, B. R., S. E. Macdonald, M. Hicks, D. L. Adams, and R. B. Hodgetts. 1999. Effect of reforestation methods on genetic diversity of lodgopole pine: an assessment using microsatellite and randomly amplified polymorphic DNA markers. Theor. Appl. Genet. 98: 793 - 801 .

Treuren, R. 2001. Efficiency of reduced primer selectivity and bulked DNA analysis for rapid detection of AFLP polymorphism in a range of crop species. Euphytica 117: $27-37$.

Vos, P., R. Hogers, M. Bleeker, M. Reijans, T. Lee, M. Hornes, A. Frijters, J. Pot, J. Peleman, M. Kuiper, and M. Zabeau. 1995. AFLP: a new techniques for DNA fingerprinting. Nucleic Acids Res. 23: 4407 - 4414. 